\title{
DERANGEMENTS OF THE ORGANO-VEGETATIVE NERVOUS SYSTEM AND OF THE ENDOCRINIAN SYSTEM IN ESSENTIAL GLAUCOMA
}

BY

\section{DR. HENRI LAGRANGE \\ PARIS}

THE peculiar form of "attacks" generally assumed by essential glaucoma, and particularly obvious in its acute form, and also the intermittency of the attacks noticed in the chronic form, have led many authors to the "neuropathic" conception of glaucoma, and several of them do not even hesitate to call it a diathesis. ${ }^{(z)}$ This makes it necessary to separate, in the hypertension syndrome, the pure glaucoma from the accidents of the same kind, the origin of which is infectious or neoplasic.

As "essential asthma" had to be separated from asthmatiform dyspnoea ${ }^{(2)}$, so must glaucoma be isolated from the disturbances which succeed in copying it, if its description is to be of any 
clearness. When glaucoma is studied in its pure form and at an early period, its characteristics give plainly the limits of the pathogenic problem. Whether it directly, reaches the acute form, or appears with less dramatic symptoms, it shows itself as a disease independent of the aetiological circusastances of inflammatory order which Stilling ${ }^{(3)}$ and Mauther ${ }^{(4)}$ bave brought into line. The form of glaucoma called "with intermittent outbursts" is one of these "privileged cases which have the value of spontaneous experiments, and they are sometimes capable of bringing forth the solution of physiological problems." (Widal.)

I have had the opportunity of following for several months a patient suffering from glaucomatous disturbances. The history of her illness confirms by itself the orientation of the physiopathological researches towards the study of the complex troubles which may remain grouped under the old epithet of "secretory neurosis." (Donders.)

I. Clinical Data.-I saw on May 23, 1923, at the ophthalmological consultation of the Lariboisière Hospital (Dr. Morax's ward) a young woman, Germaine P., aged 20 years, who seemed to be in perfect health, but who, four days previously, had begun to suffer deep pains in the ocular globes, which radiated to the head and the peri-orbital region, and which were accompanied by subjective troubles of the eyesight, which, normal on the left side, was reduced vo $5 / 10$ th on the right side.

Objectively, the pupil in medium mydriasis reacted well to light, the anterior chamber was of normal depth, and there was no perikeratic congestion to modify the aspect of the ocular globe. The ophthalmoscopical examination gave normal pictures (the papillae were well vasculanized, not sunken) but the right cornea had a striking oedematous and imfiltrated aspect, and the tension measured with the Schiötz tonometer was over $60 \mathrm{~mm}$. of $\mathrm{Hg}$, for the right eye, and $35 \mathrm{~mm}$. for the left.

The somatic examination of the patient also revealed several facts :

First of all an incomplete Basedow syndrome, without either exophthalmos or tremor, but characterized by a paroxysmal tachycardia $(100,110,130$ pulsations a minute), by the considerable increase of the blood pressure, 18-11 measured with the Pachon oscillometer, by the condition of the heart, which was enlarged, with the apex beat on the outer side of the nipple where something like a systolic tremor could be felt, but without any abnormal stethoscopic signs except a very loud aortic clangour.

These symptoms were accompanied by a notable exaggeration of the cutaneous and tendon reflexes, which at the knee were polykinetic, and which, at the foot, determirred a faint clonus; by an exaggeration of the dermographism, and finally by a most striking 
nervous instability; indeed, during the examination, the patient would be startled by every question, she would get pale or blush; and when lying on a bed, she would even show at times slight spontaneous muscular twitchings. I must also add that she is restless, and that her sleep is troubled by nightmares and sudden waking up. Then there were ovarian troubles. The troubles of the eyesight appeared, she said, at a moment when she was expecting her menses; however, they did not appear, a state of affairs she seemed to be accustomed to. She started menstruating at eleven, and since then this function has been characterized by a complete irregularity. Periods of four months will sometimes elapse when the catamenial crisis does not show itself by loss of blood. When the menses did appear, they were always preceded by a prodromal period of colic, and they would often last over a week. Considering the genital phenomenon alone, each period assumed a pathological character, either by its absence or by its excessive duration and the colic.

Interrogation alone showed clearly that there seemed to be some relation between the ocular troubles and the ovarian troubles; in the last six or seven years, the troubles of the eyesight and headaches would frequently appear at the moment when she was expecting her menses. The ocular symptoms would last but a short time, a few days, or more exactly a few mornings, as she always felt less troubled in the evenings. They would recur with a regularity noticed by the patient herself, because if not the constant corollary of the catamenia, they would, however, often accompany them or seem to take their place.

Finally, another group of facts could be isolated in this case. This young woman had cold extremities, fingers, toes and nose. She stated that her hands took an abnormally long time to get warm in winter, and this particularly hindered her in her profession of stenography. In the month of May, in a room with a constant and perfect temperature, this acrocyanosis was still noticeable. I found here the principal features of Raynaud's disease.

The systematic examination also revealed several peculiarities: digestion always followed by heat waves, slight attacks of urticaria occurring without any defined cause, localized to the limbs, especially the flexion folds.

The urinary tract appeared as intact (no paroxysmal haemoglobinuria), which was also the case for the respiratory tract (no asthmatiform attacks). No malformation could be found, and the hereditary and collateral antecedents were perfect. Father, mother, two brothers, and one sister were all in good health.

II. Experimental researches. - The results of several experimental researches must be added to these clinical data.

A. I was able to obtain at will a shock by cold in my patient; 
by putting her hands in water at $0^{\circ} \mathrm{C}$. I was able to make the following remarks after fifteen minutes immersion.

1. Acrocyanosis set in, which was refractory to rubbing and to usual means of warming; it reached simultaneously the fingers, toes, tip of the nose, and ears.

2. There appeared a manifest fall of the blood pressure measuring on an average 5 points (from 18-11 to 13-10, measured with the Pachon oscillometer). This fact brings this case nearer to the facts observed by Souques and Moreau ${ }^{\prime 6}$, and also by myself with Widal and Abrami ${ }^{(7)}$, in Raynaud's disease.

B. In the very middle of the attack of ocular hypertony, with a pressure exceeding $60 \mathrm{~mm}$. of $\mathrm{Hg}$. for the right eye and $45 \mathrm{~mm}$. of $\mathrm{Hg}$. for the left eye, the injection of half a milligram of adrenalin in the thigh muscles rapidly determined a lowering of the ocular tonus which fell to $27 \mathrm{~mm}$. of $\mathrm{Hg}$. for the left eye, remaining, however, over $60 \mathrm{~mm}$. of $\mathrm{Hg}$. for the right eye, i.e., inappreciable to a weight of $7.5 \mathrm{gm}$. with the Schiötz tonometer.

C. The tension having returned to normal on June 8 I submitted the patient to the Goetsche test, which gave a positive result in this case, which could be interpreted as an experimental proof of troubles of the thyroid function already found at the clinical examination. Indeed, the ingestion of $150 \mathrm{gms}$. of glucose immediately followed by an intra-muscular injection of $1 \mathrm{cc}$. of a $1 / 1000$ solution of adrenalin had the effect of increasing the tachycardia, which jumped from 100 pulsations a minute to 114 , of exaggerating the systolic tension, sending the maximal up from 18 to 20 , of provoking a glycosuria $(10.2$ gms. per litre), and of causing several general disturbances (tremor, sudation).

D. The Bordet-Wassermann blood serum test was twice negative.

III. Evolution.-The interesting part of this history appeared especially in the course of the evolution.

Confronted by this considerable increase in the ocular tension, I could not remain indifferent, and I started at first on a local treatment followed by a general treatment.

The local treatment in the form of instillations of eserin and pilocarpin remained absolutely unavailing up to May 27. At that date, after the intramuscular injection of adrenalin, I noticed a lowering of the ocular tension on the left side only. It came to normal for both eyes on May 31 : R.E., $27 \mathrm{~mm}$. of Hg.; L.E., $27 \mathrm{~mm}$. of $\mathrm{Hg}$., and at the same time, the vision of the right eye came back to normal, equal therefore to the vision of the left eye. On June 1 the ocular tension of the right eye went even down to $23 \mathrm{~mm}$. of $\mathrm{Hg}$. and things remained for a certain length of time in this condition. 
Considering the facts observed by Th. Alajouanine and Jacques Lermoye $z^{(8)}$, I treated my patient by a series of intramuscular injections of corpus luteum (a total of 1 gramme 40) given daily from June 15 to June 22 at which time the intraocular tension of both eyes had returned to normal (T.R.E., $25 \mathrm{~mm}$. of Hg., T.L.E., $27 \mathrm{~mm}$. of $\mathrm{Hg}$.) and during the week the date when the menses were expected.

But on June 23 menses appeared painful and scanty, and the ocular tension went up again :

\begin{tabular}{lrlllclc} 
& & & \multicolumn{3}{c}{$\begin{array}{c}\text { T.R.E. } \\
\text { mm. of } \text { Hg. }\end{array}$} & \multicolumn{2}{c}{$\begin{array}{c}\text { T.L.E. } \\
\text { mm. of } \mathbf{H g} .\end{array}$} \\
June 29 & $\ldots$ & $\ldots$ & $\ldots$ & 37 & $\ldots$ & 40 \\
July & 2 & $\ldots$ & $\ldots$ & $\ldots$ & 37 & $\ldots$ & 45 \\
July & 3 & $\ldots$ & $\ldots$ & $\ldots$ & 35 & $\ldots$ & 40 \\
July & 4 & $\ldots$ & $\ldots$ & $\ldots$ & 35 & $\ldots$ & 40
\end{tabular}

However on July 6, the blood Iosses which had begun a fortnight previously stopped, and the ocular tension had gone down : T.R.E., $23 \mathrm{~mm}$. of Hg., T.L.E., $27 \mathrm{~mm}$. of $\mathrm{Hg}$., thus returning to an almost normal figure without the aid of either local or general treatment. The attack of glaucoma which began on May 23, 1923, at the date when the menses should have begun, thus ceased during 23 days (from June 1 to 23) without the help of any other treatment but opotherapy, but it recurred plainly at the time of the next catamenial period (which itself kept a pathological character in its duration) and ceased with it.

During the following months, the attacks of glaucoma reappeared with a variable intensity, but on a parallel line with the menstrual troubles, and the good effect of the opotherapic treatment on the latter had a most fortunate effect on the ocular troubles.

At the present moment, twenty-one months after the beginning of this history, this young woman has been able to avoid any severe glaucomatous accident for over fourteen months without having had to have recourse to miotics, by the sole effect of an intensive opotherapic treatment which had besides the best of actions on the genital troubles.

The appended table, Fig. 1, which gives the measures of the ocular tensions taken on my patient in the course of an almost continuous observation during about ten months, shows at the same time the synchronism of the attacks of glaucoma and of the menstrual periods, the parallelism of the pathological character of the latter and of the intensity of the ocular troubles, and the simultaneous influence of the ovarian treatment on both.

Severe troubles reappeared in July, notwithstanding the treatment.

In August there was a new attack during the interruption of the treatment. 
In September, the opotherapic treatment acted only on the menses, but little by little the rhythm of the periods returned to normal and the glancomatous attacks also disappeared: I never was able to detect them during a period independent from the menstrual period.

The history of this case brings together various phenomena of pluri-glandular disturbances, and one of them, the catamenial phenomenon seems to link to its flow some kind of ocular troubles which are in this case the attacks of glaucoma. It is besides of no small importance to observe the association of a Basedowian syndrome, of ovarian insufficiency and of Raynaud's disease.

The suggestions of $\mathrm{Hertel}^{(9)}$ and Wessely ${ }^{\left({ }^{(0)}\right)}$, relative to the rôle of the functions of the thyroid gland in ophthalmotonus, and the facts noticed by Marx ${ }^{(12)}$, and Salvati ${ }^{(1)}$, relative to the physiological variations which can be observed in the ocular tonus during the menstrual periods or the state of pregnancy, all add to the interest of the facts I observed in my patient.

This is an ensemble of facts which are brought together so as to show the close relation associating the mechanism regulating the ocular tension and the activity of endocrinian glands, of which Langdon Brown ${ }^{\left({ }^{(3)}\right)}$ thought he could say in an aphoristic form, that their action was like a draught on a fire.

A. C. Guillaume and Godel ${ }^{\left({ }^{4}\right)}$ have shown in recent works that the organo-vegetative nervous balance of the woman is in various degrees incessantly disturbed by the influence of the catamenia. A close observation of patients for several months shows that from one "period" to another a succession of identical phases of the organo-vegetative loss of balance will appear. In the two weeks preceding the apparition of the menstrual haemorrhage there progressively appears a state of vagotony followed by a state of sympatheticotony in the four or five days which immediately precede the beginning of the menses. The latter ends suddenly a few hours before haemorrhage and is followed by a vagotony which lasts for several days, at the end of which normal balance is restored. Then the cycle begins all over again.

Phases characterized by modifications, in the same physiopathological line, of blood pressure, of capillary tension, of local arterial reactions, of the rate of local utilisation of oxyhaemoglobin, of sensitivo-organo-vegetative reflexes, of fundamental metabolism, of modifications of the visceral functions of this character, etc., occur.

These signs of loss of balance are more or less marked according to the patients considered, and the absence of menstrual haemorrhage (dysmenorrhoea) does not stop the production of the phases of loss of balance. It seems, besides, that the exaggeration of the signs of instability is linked in this case with disturbances of the function of the endocrinian glands (principally thyroid and ovary). 
404 The British Journal of Ophthalmology

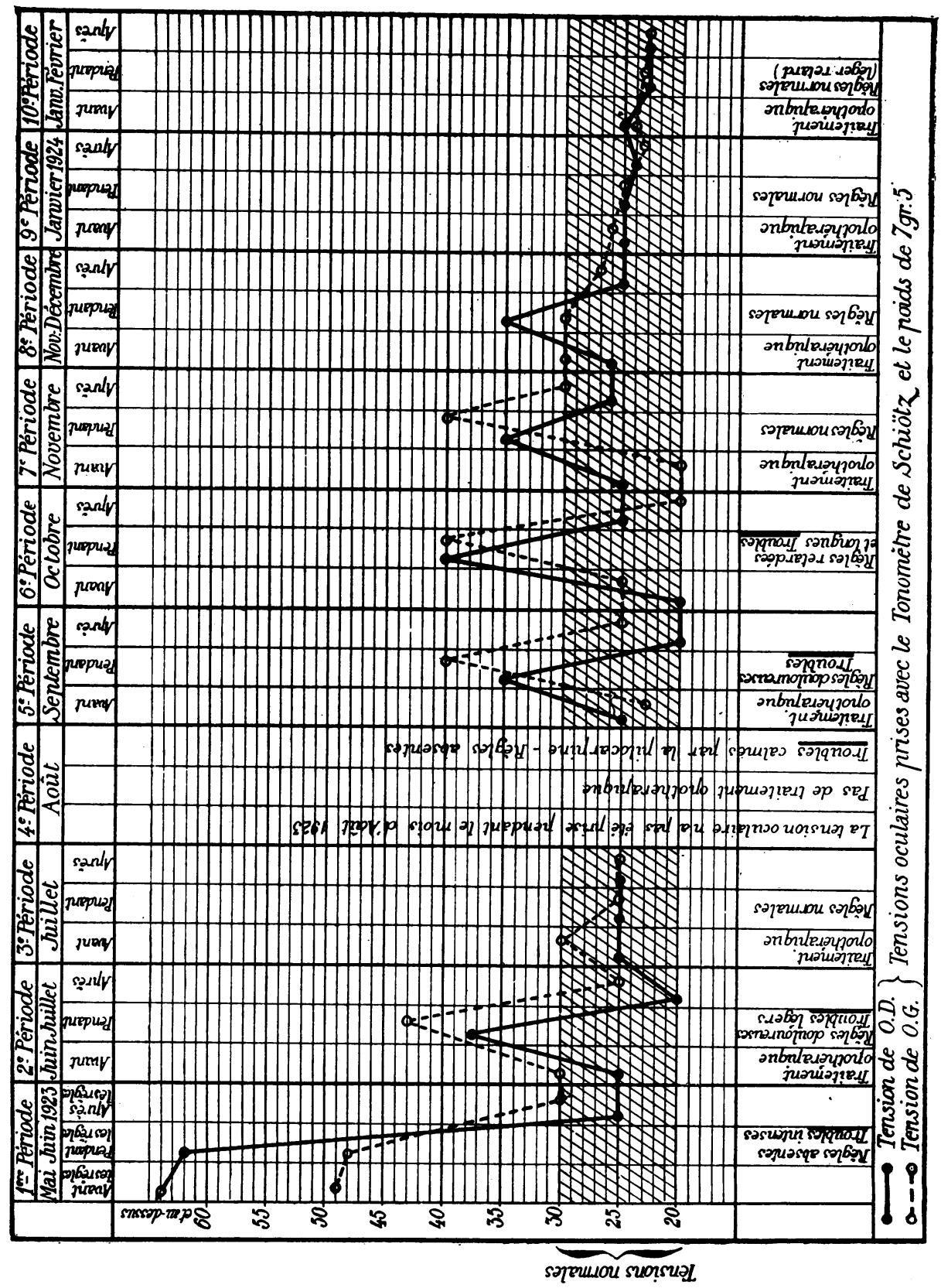


Derangements of Organo-Vegetative Nervous System 405
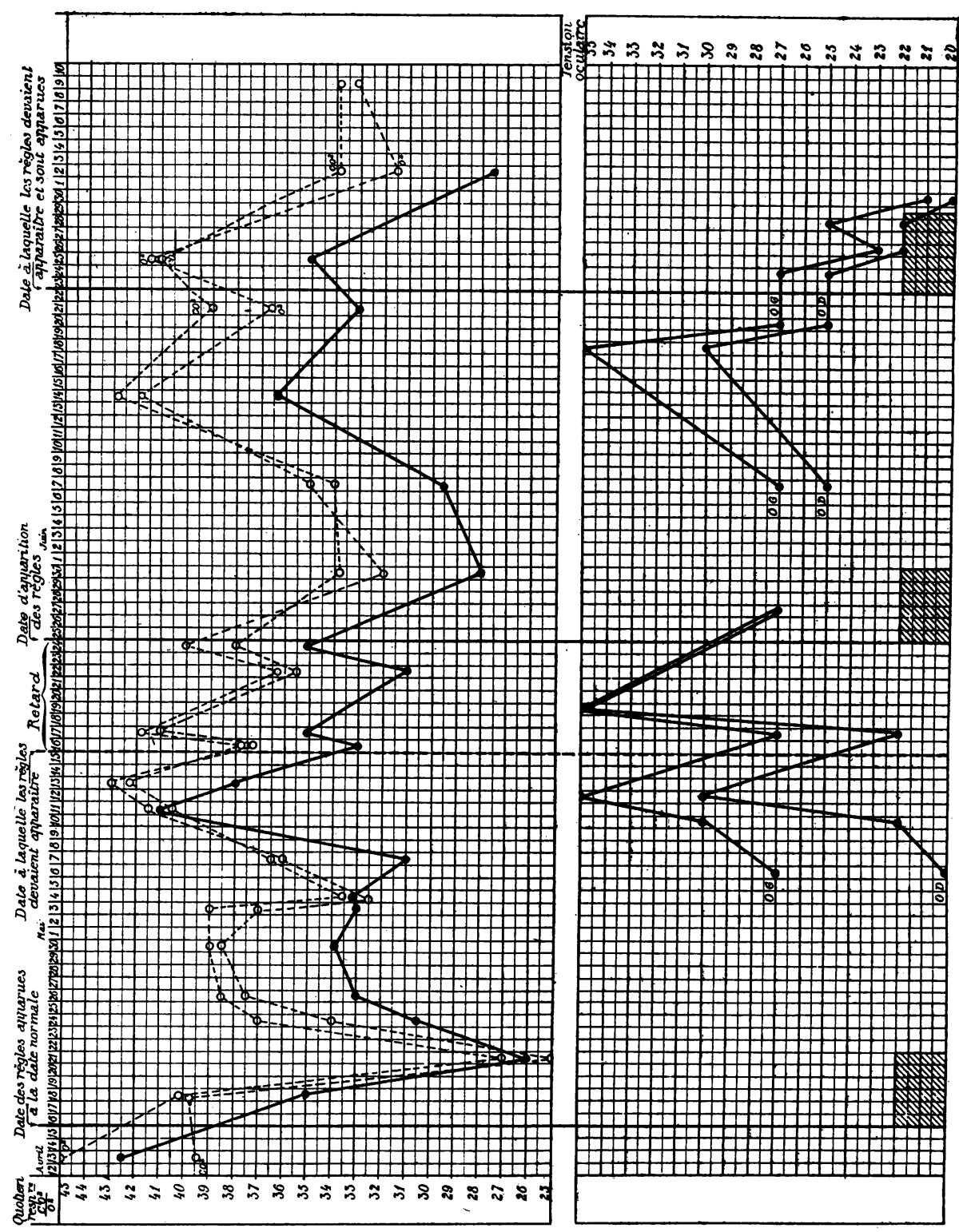
The observations, which were made in this case of intermittent juvenile glaucoma, and those made by A. C. Guillaume concerning the variations of the organo-vegetative balance of women, have led me to pursue the study of the latter in collaboration with this author so as to define with precision the meaning of the endocrinian and organo-vegetative reactions in order to mark the eventual relations between these reactions and the outbursts of glaucoma. ${ }^{\left({ }^{(5)}\right)}$

The examination of this patient bears on two successive phases:

(a) A first phase during which she did not follow any treatment. (Suppression of the ovarian treatment.)

(b) A second phase during which the opotherapic treatment was again applied. (Injection of extracts of ovary.)

During the first phase we noticed:

1. The existence in no small degree of the usual succession of phases of the organo-vegetative loss of balance shown on our graph by the variations of the fundamental metabolism. On the appended curve, Fig. 2, we noticed, on a parallel line, coinciding exactly with the period of hypersympatheticotony, an outburst of ocular hypertension which disappeared as soon as the organo-vegetative reactions became vagotonic.

2. That, during that period when no ovarian treatment was given, the menstrual periods did not appear at their normal date, but appeared ten days later.

3. That this delay in the start of the menstrual flow did not prevent the patient from showing at the normal periods (in relation to the date when the haemorrhage should have appeared) the succession of phases of the organo-vegetative reaction. These phases were accompanied by parallel modifications of the ocular tonus: and this explains that, in several circumstances, we were able to notice the coincidence of the glaucomatous attacks with the manifestations of the menstrual molimen, independently of the presence or absence of the haemorrhagic flow at the anticipated period.

4. We must add finally that during the whole period of delay, and of the beginning of the flow, the patient remained, with slight oscillations, in a state of hypersympatheticotony and ocular hypertension which increased the day before the haemorrhage and which was then replaced by a state of vagotony and a fall of the ocular tension as soon as the haemorrhage started.

5. In the second phase of our observation, the opotherapic treatment having been applied, we were able to inscribe an equally parallel curve concerning the variations of the ocular tonus, and those of the fundamental metabolism. And although these variations are still of a somewhat abnormal character in their intensity, it must be noted that the opotherapic treatment seems to have prevented a delay (which during the first phase of our observation had 
been of ten days) characterized by a state of hypersympatheticotony rigorously parallel with a rise of the ocular tension.

These statements confirm the conclusions I had given previously, underlining the closeness of the relations linking together the loss of balance of the organo-vegetative nervous system (of the vago-sympathetic) and the endocrinian functions. They state, at the same time as they explain their mechanism, the dependence of the outbursts of glaucoma noticed in our patient, in relation to the endocrinian and sympathetic troubles: they show the existence of the eventual relation of cause to effect between the outbursts of ocular hypertension and the states of organo-vegetative and endocrinian loss of balance.

Whatever the importance of the rôle played by the endocrinian glands, it is not possible to say at the present moment if their alterations are the starting point of all these disturbances, or if they have only an intermediary rôle. But the mechanism of the attack of glaucoma seems to be linked in its ensemble to a disturbance of the innervation system of the ocular globe. In an attack of asthma, adrenalin, by acting on the sympathetic, will cause the cessation of the bronchial spasm, and will activate the catarrhal termination; in the attack of glaucoma, as we observed it in Germaine P., the injection into the crural quadriceps of $1 / 2 \mathrm{mgr}$. of a $1 / 1000$ solution of adrenalin was able to lower the tension of the ocular globe from $45 \mathrm{~mm}$. of $\mathrm{Hg}$. to $27 \mathrm{~mm}$. of $\mathrm{Hg}$. This fact has a documentary importance which we are obliged to emphasize. It is the connecting link between the glaucomatous attack and certain elements of the anaphylactic shock, such as urticaria, asthma, Raynaud's disease, spasmodic coryza.

The attack of glaucoma seems to me for other reasons to be related to these various manifestations of the colloidoclasic diathesis. In the course of recent researches, Weekers ${ }^{(16)}$ was able to obtain experimentally in the rabbit the outbursts of ocular hypertony by parenteral injections of distilled water. He attributes these results to the decrease of the molecular concentration of the blood, and to the modification of the intraocular liquid, but in his observations the local attack always seemed to be accompanied by severe general disturbances which frequently ended by killing the animal. These phenomena which he attributes to a "toxic effect" seemed to me to be linked with the shock which is bound to follow these injections; thus the temporary ocular hypertony which accompanies them is an experimental fact which is in accord with my personal observations on the modification of the ophthalmotonus, consecutive in certain patients, to therapeutical intravenous injections. It is not rare, indeed, to see that injections of cyanide of 
mercury. or of arsenical products have the effect of momentarily modifying the ocular tension. These facts are worth while being grouped with the clinical observations which I have just reported, as they constitute an ensemble of which each element contributes to show the character of "crisis" of these attacks of glaucoma.

"At the base and at the beginning of every primary glaucoma, there is an intervention of the sympathetic nerve or, if one wants to be less precise, of the secretory nerves." ${ }^{\left({ }_{17}\right)}$ This sentence will form my conclusion, because I do not believe that I am in a position to define the rôle of the sympathetic, and to dissociate the sympathetic and para-sympathetic actions of this system.

Just as the bronchial spasm, an essential symptom of the first phase of typical asthma, seems to be under the influence of a hypervagotony followed by phenomena due to the subsequent action of the sympathetic, for a moment inhibited, so in glaucoma, the effect produced by an injection of a therapeutical agent, a stimulant of the sympathetic, seems to indicate that the ocular hypertension is linked in this case to the loss of balance of the sympathetic and para-sympathetic actions. But the result obtained in my patient cannot be interpreted as a local reaction, such a conception having been started in ophthalmology by the happy effects of the retrobulbar injection of novocain-adrenalin, because the latter seem in my case to have found their origin in the action of this therapeutical agent on the myo-neural point of the unstriated muscle fibres.

\section{BIBLIOGRAPHY}

1. Lagrange, Felix.-Presse Médicale, June 24, 1922.

2. F. Widal, M. Lermoyez, Et. Brissaud and P. Abrami.-Presse Médicale, July 11, 1924.

3. J. Stilling.-" "Zur Theorie des Glaukoms." Arch. f. Ophthal., Vol. XIV, Part iii, p. 259, 1868.

4. Mauthner. - "Glaukomtheorien und Secondar-Glaukom. Wiesbaden, 1882.

5. Lagrange, Henri.-Soc. d'Ophtal. de Paris, July, 1923 : Presse Médicale, April 5, 1924 .

6. Soques and Moreau.-Acad. de Médicine, July 20, 1920.

7. Unpublished Clinical Lecture of Prof. F. Widal, mentioned by J. Lermoyez in "Les phenomenes de choc et le coryza spasmodique." Plon-Nourrit edition, p. 82, 1922.

8. Lermoyez, Jacques.-Loc. cit., p. 93.

9. Hertel._-"Weiterer Beitrag zur Lehre vom Augendruck." 41 Bericht, Heidelberg, p. 57, 1918.

10. Wessely.-Loc. cit., p. 80 .

11. Salvati.-Ann. d'Ocul., Vol. CLX, p. 468, July, 1923.

12. Marx.-Ann. d'Ocul., Vol. CLX, p. 873, November, 1923.

13. Brown, Langdon.- “The Sympathetic System in Diseases." London, 1920.

14. Guillaume, A. C., and Godel.-Soc. de Biologie, March 8, 1924.

15. Guillaume, A. C., and Lagrange, Henri.-Soc. d'Ophtal. de Paris, July, 1924.

16. Weekers.-Arch. d'Ophtal., p. 85, February, 1924.

17. Lagrange, Felix.- "Du glaucome et de l'Hypotonie." G. Doin edition, p. 103, 1922. 